\title{
A Salute to the Knowledge Gained with Elsevier Publishing
}

$\mathrm{T}$ This "double issue" of Cornell Quarterly is special in a number of ways. Most obviously, it is quite lengthy. Given the amount of material for this issue, we decided to make this a combined issuc, and thus this represents the October-Decomber 2003 issue (numbers 5 and 6 of volume 44). But besides its length, the timing of this issue is also noteworthy. This is the final issuc of Cornell (2uarterly to be published by Elsevicr. The reasons and benefits of this change will be discussed in our next issuc; however, I did want to mention this important point. Furthermore, as this marks the end of an impressive run, I wanted to end this relationship by looking back over Elsevier's publishing tenure, and provide a salute to the content that CQ has printed over this time.

Our publishing relarionship with Elsevier cnds after 12 years, 73 issues, and 723 feature articles. Over this time $C Q$ has helped disseminate some truly valuable advances for the practice of hospitality. With the help of my editorial board and the faculty of the Corncll Universicy School of Hotel Administration, I sought nominations for particularly special articles that were worth highlighting. Originally, the idea was to reprint these articles and solicit commentaries and updates on their content. Many articles were nominated - too many for one issue. Glenn Wirhiam and I went through these nominations and invited commentaries on six of the papers. I am pleased to report that not only were commentaries written on all six of these papers, but as you will see, most of those were written by the authors of the original papers. I hope that you will agree that these updares, reprinted with each of the original articles, helps provide a valuable perspective on the type of information gained through CQ articles, how this content has made important predictions and discoveries that were important for the practice of hospitality, and how even this arguably "old" material is still relevant today.

In addition to specific article nominations, I also received a number of nominarions for sets of articles that covered specific topics. These included series of
From the Editor

articles on revenue management, labor scheduling, best practices, tipping, customerchoice modeling, revenuc enhancement, and customer sat-

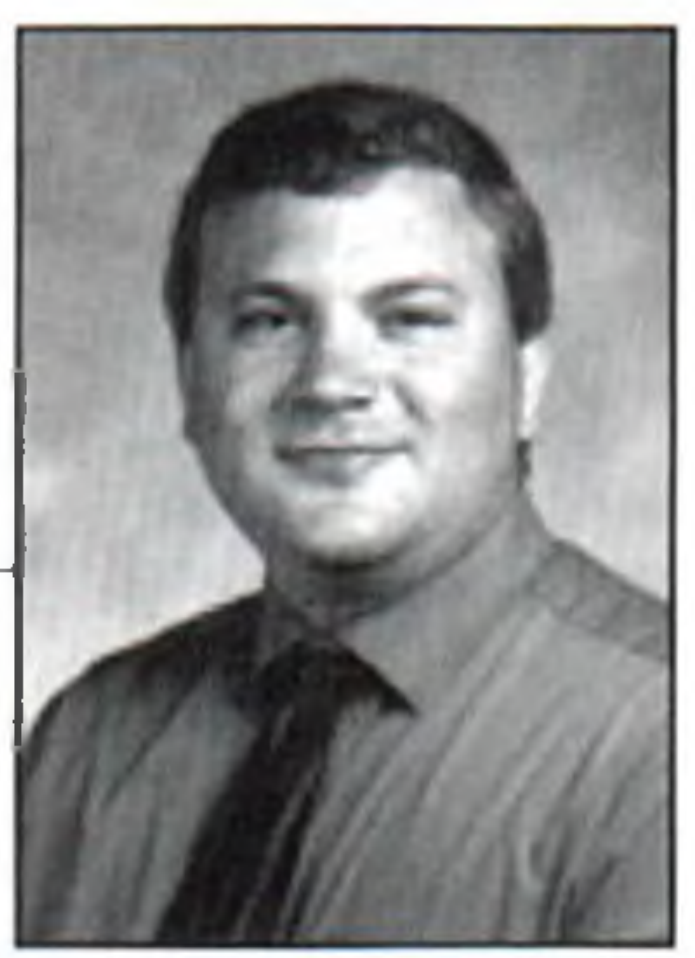

Michael C. Sturman isfaction. Each of these ropics was examined in numerous articles during Elsevier's publishing tenure. It was clearly impractical for us to reprint all of the relevant articles, but we did want to pay tribute to these series of finc work. Thus, we decided to invite commentarics on these various topics from the authors who contributed substantially to these areas in past CQ publications. This issue benefits from the publication of eight such commentaries.

Please note that while this issue highlights some content judged to be particularly valuable, it is not my intent to represent this number as a "best of" issue. There were many more nominations and noteworthy arricles than we could reasonably reprint or for which we could solicit commentaries. Our years with Elsevier yielded a bounty of insights for the study and practice of hospitality. This issue is but a taste of those offerings.

If you are a long-rime reader of $C(Q$, you will certainly have noted that the style and content of $C(Q$ has evolved over cime. Given the dynamic nature of the hospitality ficld and the advances being made in hospitality research, education, and practice, we will continue to make changes. Yet there is often value to looking to the past and reflecting on some of the contributions that have helped us learn. The contents of this issue represent but a subset of the past dozen years of material, but even this sampling helps to show some of the considerable learning that has occurred in our field.

In closing, with this issue, we are saying "good bye" to Elsevier. It is my hope that this issue ends our relationship on a high note, with an issue that appropriarely salutes the past, while it gives readers valuable and practical ideas for the future. I' hank you, Elsevicr. We have learned a lot.-M.C.S. 